\title{
Amino Acid Metabolism in Exercising Man
}

\author{
Phimip Felig and John Wahren \\ From the Department of Internal Medicine, Yale University School of Medicine, \\ New Haven, Connecticut 06510, and the Department of Clinical Physiology \\ of the Karolinska Institute at the Seraphimer Hospital, Stockholm, Sweden
}

A B S T R A C T Arterial concentration and net exchange across the leg and splanchnic bed of 19 amino acids were determined in healthy, postabsorptive subjects in the resting state and after 10 and $40 \mathrm{~min}$ of exercise on a bicycle ergometer at work intensities of 400,800 , and $1200 \mathrm{~kg}-\mathrm{m} / \mathrm{min}$. Arterio-portal venous differences were measured in five subjects undergoing elective cholecystectomy.

In the resting state significant net release from the leg was noted for 13 amino acids, and significant splanchnic uptake was observed for 10 amino acids. Peripheral release and splanchnic uptake of alanine exceeded that of all other amino acids, accounting for $35-40 \%$ of total net amino acid exchange. Alanine and other amino acids were released in small amounts (relative to net splanchnic uptake) by the extrahepatic splanchnic tissues drained by the portal vein.

During exercise arterial ananine rose $20-25 \%$ with mild exertion and $60-96 \%$ at the heavier work loads. Both at rest and during exercise a direct correlation was observed between arterial alanine and arterial pyruvate levels. Net amino acid release across the exercising leg was consistently observed at all levels of work intensity only for alanine. Estimated leg alanine output increased above resting levels in proportion to the work load. Splanchnic alanine uptake during exercise exceeded that of all other amino acids and increased by 15-20\% during mild and moderate exercise, primarily as a consequence of augmented fractional extraction of alanine. For all other amino acids, there was no change in arterial concentration during mild exercise. At heavier work loads, increases of $8-35 \%$ were noted for isoleucine, leucine, methionine, tyrosine, and phenylalanine, which were at-

This work was presented in part at the 62nd Annual Meeting of the American Society for Clinical Investigation, 4 May 1970, Atlantic City, N. J., and at the Karolinska Institute Symposium on "Muscle Metabolism During Exercise," September 1970, Stockholm, Sweden (1).

Dr. Felig is a Teaching and Research Scholar of the American College of Physicians.

Received for publication 3 June 1971 and in revised form 22 July 1971. tributable to altered splanchnic exchange rather than augmented peripheral release.

The data suggest that (a) synthesis of alanine in muscle, presumably by transamination of glucose-derived pyruvate, is increased in exercise probably as a consequence of increased availability of pyruvate and amino groups; (b) circulating alanine serves an important carrier function in the transport of amino groups from peripheral muscle to the liver, particularly during exercise; (c) a glucose-alanine cycle exists whereby alanine, synthesized in muscle, is taken up by the liver and its glucose-derived carbon skeleton is reconverted to glucose.

\section{INTRODUCTION}

The role of carbohydrate and lipid metabolism in the fuel economy of resting and exercising muscle has been extensively investigated in intact man $(2,3)$. Although it has long been recognized that muscular work is also accompanied by peripheral release of ammonia $(4,5)$, little information is available regarding amino acid metabolism in exercise.

Our interest in examining amino acid metabolism in exercise was stimulated by recent studies demonstrating that alanine is released by resting forearm muscle to a greater extent than all other amino acids $(6,7)$. Since alanine comprises only $5-7 \%$ of the amino acid residues in muscle protein (8), peripheral synthesis of alanine by transamination of glucose-derived pyruvate has been suggested (6). Furthermore, inasmuch as alanine is quantitatively the primary amino acid extracted by the splanchnic circulation (9) and is readily converted by the liver to glucose $(10,11)$, a glucose-alanine cycle involving muscle and liver has been postulated $(6,11)$. By this formulation, peripheral formation and release of alanine would depend not only on muscle protein dissolution but also on the rate of pyruvate formation from glucose and the availability of amino groups for transamination. 
The present study was designed to test this hypothesis and to characterize further the pattern and regulation of peripheral and splanchnic amino acid exchange in intact man by examining amino acid metabolism during exercise, a situation in which glucose utilization (2) and peripheral ammonia formation are stimulated $(4,5)$. The influence of mild, moderate, and severe exercise on the level of circulating amino acids and on the net balance of amino acids across the exercising leg and the splanchnic vascular bed has been investigated. In addition, the relation of arterial alanine concentration to pyruvate levels has been examined. Finally, since previous studies failed to exclude the possible contribution of extrahepatic amino acid extraction to net splanchnic amino acid uptake (9), arterial-portal venous differences for individual amino acids were determined in five subjects undergoing elective cholecystectomy. Data on peripheral and splanchnic glucose, lactate, and pyruvate balance in the exercised subjects are reported separately (2).

\section{METHODS}

Subjects. The subjects were 18 healthy, adult male volunteers. Three were students; all the others were employed by the Stockholm fire department. Data for age, height, and weight are given in Table I. One of the subjects (B. D.) was studied on two occasions at different work loads. None of the subjects participated in training programs or competitive athletics on a regular basis. All of the subjects were informed of the nature, purpose, and risks involved in the study before their participation.

Catheterization, exercise, and blood flow. The studies were performed in the morning after an overnight fast $(10-14 \mathrm{hr})$. Teflon catheters with an outer diameter of 1.2 $\mathrm{mm}$ were inserted percutaneously into a brachial artery, a femoral vein, and an antecubital vein. In 12 of the subjects (4 subjects at each exercise load) a Goodale-Lubin catheter (No. 7 or 8) was also inserted in an exposed antecubital vein and advanced to a main right hepatic vein under fluoroscopic control. The catheter tip was placed $3-4 \mathrm{~cm}$ from the wedge position, and its location was checked repeatedly by fluoroscopy before and after the exercise period. The catheters were kept patent by intermittent flushing with saline; in the case of the hepatic venous catheter flushing was done with $0.5 \%$

TABLE I

Clinical Data, Oxygen Uptake, and Estimated Leg Blood Flow at Rest and after 10 and 40 min of Leg Exercise at Various Work Intensities

\begin{tabular}{|c|c|c|c|c|c|c|c|c|c|c|c|c|}
\hline \multirow[b]{3}{*}{ Subject } & \multirow[b]{3}{*}{ Age } & \multirow[b]{3}{*}{ Height } & \multirow[b]{3}{*}{ Weight } & \multicolumn{3}{|c|}{ Oxygen uptake } & \multicolumn{3}{|c|}{ A-FVo,* } & \multicolumn{3}{|c|}{ Estimated leg blood flow } \\
\hline & & & & \multirow[b]{2}{*}{ Rest } & \multicolumn{2}{|c|}{ Exercise } & \multirow[b]{2}{*}{ Rest } & \multicolumn{2}{|c|}{ Exercise } & \multirow[b]{2}{*}{ Rest } & \multicolumn{2}{|c|}{ Exercise } \\
\hline & & & & & $\begin{array}{c}10 \\
\min \end{array}$ & $\begin{array}{c}\mathbf{4 0} \\
\min \end{array}$ & & $\begin{array}{c}10 \\
\min \end{array}$ & $\begin{array}{l}\mathbf{4 0} \\
\min \end{array}$ & & $\begin{array}{c}10 \\
\text { min }\end{array}$ & $\begin{array}{c}40 \\
\min \end{array}$ \\
\hline & $y r$ & $c m$ & kg & & $\mathrm{ml} / \mathrm{min}$ & & & $\mathrm{ml} / \mathrm{liter}$ & & & liters/min & \\
\hline \multicolumn{13}{|c|}{ Mild exercise $(400 \mathrm{~kg}-\mathrm{m} / \mathrm{min})$} \\
\hline L. N. & 36 & 167 & 64 & 249 & 946 & 1035 & 55.3 & 133.6 & 140.2 & 1.08 & 4.20 & 4.46 \\
\hline B. D. & 29 & 190 & 81 & 316 & 984 & 946 & 76.2 & 137.1 & 133.2 & 0.99 & 4.06 & 3.97 \\
\hline U. S. & 27 & 189 & 79 & 278 & 861 & 1139 & 74.7 & 150.3 & 162.2 & 0.89 & 3.24 & 4.23 \\
\hline J. L. & 28 & 176 & 67 & 228 & 812 & 1025 & 60.3 & 143.4 & 152.6 & 0.91 & 3.31 & 4.12 \\
\hline G. E. & 52 & 182 & 86 & 302 & 1036 & 1093 & 101.6 & 169.8 & 167.4 & 0.71 & 3.54 & 3.84 \\
\hline K. C. & 42 & 179 & 80 & 231 & 967 & 833 & 119.2 & 164.0 & 148.4 & 0.47 & 3.57 & 3.29 \\
\hline T. L. & 41 & 184 & 80 & 314 & 1143 & 1163 & 72.4 & 160.7 & 158.8 & 1.04 & 4.18 & 4.32 \\
\hline G. K. & 45 & 173 & 65 & 223 & 899 & 892 & 60.6 & 149.5 & 148.7 & 0.88 & 3.61 & 3.60 \\
\hline R. S. & 48 & 180 & 84 & 264 & 931 & 1094 & 72.2 & 142.6 & 149.4 & 0.88 & 3.81 & 4.42 \\
\hline \multicolumn{13}{|c|}{ Moderate exercise $(800 \mathrm{~kg}-\mathrm{m} / \mathrm{min})$} \\
\hline I. L. & 46 & 174 & 64 & 203 & 1649 & 1764 & 57.0 & 173.9 & 183.0 & 0.85 & 6.27 & 6.41 \\
\hline L. P. & 24 & 176 & 71 & 295 & 1859 & 1860 & 55.1 & 129.3 & 127.9 & 1.28 & 9.26 & 9.36 \\
\hline L. P. P. & 31 & 177 & 74 & 223 & 1511 & 1602 & 73.4 & 186.1 & 179.7 & 0.73 & 5.27 & 5.82 \\
\hline R. R. & 25 & 172 & 65 & 251 & 1645 & 1696 & 58.6 & 131.3 & 154.7 & 1.03 & 8.10 & 7.11 \\
\hline L. L. & 38 & 184 & 79 & 263 & 1556 & 1597 & 52.3 & 168.2 & 169.7 & 1.21 & 5.91 & 6.03 \\
\hline \multicolumn{13}{|c|}{ Severe exercise $(1200 \mathrm{~kg}-\mathrm{m} / \mathrm{min})$} \\
\hline C. G. & 26 & 184 & 71 & 218 & 2288 & 2397 & 82.9 & 158.5 & 155.8 & 0.63 & 9.73 & 10.41 \\
\hline O. K. & 25 & 178 & 79 & 213 & 1622 & 2192 & 76.0 & 140.4 & 156.1 & 0.67 & 7.59 & 9.46 \\
\hline S. L. & 29 & 182 & 76 & 282 & 2379 & 2442 & 95.3 & 148.6 & 150.4 & 0.71 & 10.62 & 10.79 \\
\hline G. J. & 29 & 181 & 81 & 240 & 2506 & 2902 & 52.0 & 145.9 & 150.9 & 1.11 & 11.58 & 13.08 \\
\hline B. D. & 29 & 190 & 81 & 256 & 2598 & 2727 & 55.9 & 149.2 & 167.9 & 1.00 & 11.71 & 10.96 \\
\hline
\end{tabular}

* $\mathrm{A}-\mathrm{FVO}_{2}=$ arterio-femoral venous difference for oxygen.

$\ddagger$ Total blood flow to both legs. 
sodium citrate in isotonic saline. Heparin was not administered to the subjects during the study.

After introduction of the catheters, the subjects were studied at rest in the supine position, and during upright exercise on a bicycle ergometer (Elema Schönander, Stockholm, Sweden). They exercised for $40 \mathrm{~min}$ at work intensities of 400 ("mild" exercise), 800 ("moderate" exercise), or 1200 ("severe" exercise) $\mathrm{kg}-\mathrm{m} / \mathrm{min}(1 \mathrm{~kg}-\mathrm{m} / \mathrm{min}=0.163 \mathrm{w}$ ). Blood samples for amino acid analysis were collected simultaneously from the brachial artery and the femoral and hepatic veins at rest and after 10 and $40 \mathrm{~min}$ of exercise. Expired air was collected at the same time intervals for determination of oxygen uptake.

Hepatic blood flow was measured at rest and during exercise by the continuous infusion technique (12) using indocyanine green dye (13). The infusion was performed for $30 \mathrm{~min}$ with the subjects at rest in the supine position and then continued throughout the exercise period with the subjects in the upright position. Simultaneous arterial and hepatic venous samples for determination of dye concentration were collected $15 \mathrm{~min}$ after the dye infusion was initiated, and at 5 -min intervals thereafter, both at rest and during exercise. At the heavier work loads several subjects displayed a rise in the arterial concentration of dye. For the calculation of blood flow in these subjects, the rate of rise for plasma dye content was subtracted from the rate of dye infusion. This correction factor did not exceed $0.04 \mathrm{mg} / \mathrm{liter}$ per $\mathrm{min}$ in any subject, indicating that significant hepatic storage is unlikely to have occurred (14).

Total blood flow to both legs at rest and during exercise was estimated by the Fick method from the total oxygen consumption and oxygen uptake across the legs according to the formulas of Jorfeldt and Wahren (15):

$$
\begin{aligned}
& \mathrm{F}_{\mathrm{R}}=0.24 \dot{\mathrm{Vo}} \mathrm{o}_{\mathrm{R}} / \mathrm{A}-\mathrm{FVo} \mathrm{o}_{\mathrm{R}} \\
& \mathrm{F}_{\mathrm{E}}=\frac{0.24 \dot{\mathrm{Vo}}_{2_{\mathrm{R}}}+0.72\left(\dot{\mathrm{Vo}}_{2_{\mathrm{E}}}-\dot{\mathrm{Vo}}_{2_{\mathrm{R}}}\right)}{\mathrm{A}-\mathrm{FVo} \mathbf{2}_{\mathbf{E}}} .
\end{aligned}
$$

In these equations $\mathrm{F}$ represents total blood flow to both legs, the subscripts $R$ and $E$ refer to rest and exercise respectively, A-FV $\mathrm{O}_{2}$ represents the arterio-femoral venous difference for oxygen, and $\mathrm{V}_{\mathrm{O}_{2}}$ indicates the oxygen consumption. In the calculations it is assumed that $24 \%$ of the total oxygen consumption at rest and $72 \%$ of the increase in oxygen uptake observed during exercise are distributed to the legs. The validity of these assumptions derives from studies of leg blood flow by the dye dilution technique in healthy subjects at rest and during leg exercise at work intensities identical with those employed in the present study (15)

Portal vein study. Five patients (28-46 yr of age) were studied in the postabsorptive state (12-14 hr fast) at the time of elective cholecystectomy for uncomplicated cholelithiasis. A brachial artery catheter was inserted percutaneously before surgery. During the surgical procedure simultaneous blood samples were obtained from the arterial catheter and by direct needle puncture from the portal vein. General anesthesia with halothane was employed; no glucose was infused before obtaining the blood samples from amino acid analysis.

Chemical analyses. The methods employed for determination of individual plasma amino acids, and blood lactate and pyruvate have been described previously (16). Blood samples for analysis of oxygen saturation and hemoglobin concentration were drawn into $10-\mathrm{ml}$ siliconized glass syringes. The dead space in the syringes was filled with heparin (5000 $\mathrm{IU} / \mathrm{ml}$ ). Oxygen saturation was determined spectrophoto-

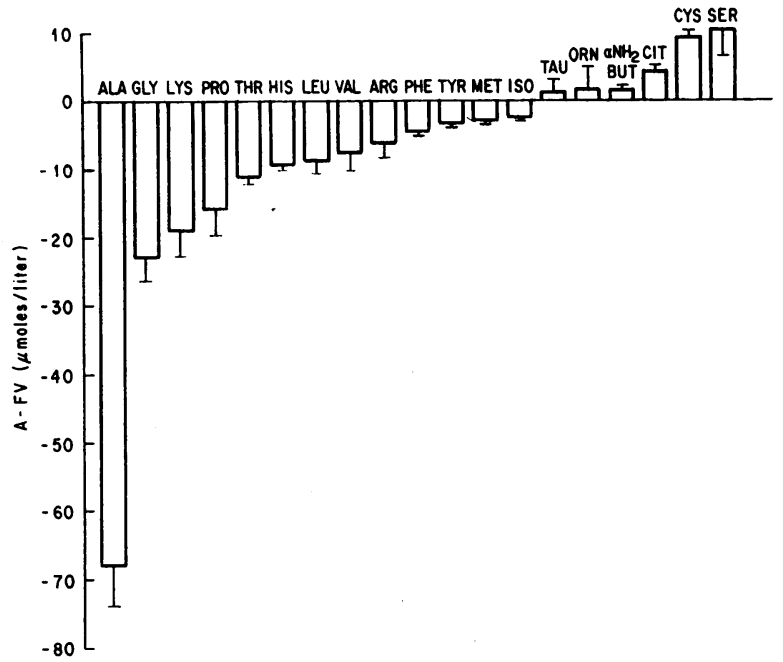

Figure 1 Net balance of individual amino acids across the leg (arterio-femoral venous differences, A-FV) in 19 subjects in the resting, postabsorptive state. The lines at the top or bottom of the bars represent the standard error of the mean. The mean A-FV differences were significantly different from zero for all amino acids except taurine and ornithine.

metrically by modification of the method of Drabkin (17). Hemoglobin concentration was measured by the cyanomethemoglobin technique (18). Oxygen concentration was determined in expired air collected in Douglas bags by the Scholander microtechnique. The paired $t$ test and calculation of the coefficient of correlation were employed in the statistical analyses (19).

\section{RESULTS}

Amino acid metabolism in the resting state. In the resting state, a negative arterio-femoral venous difference, indicating net substrate release by leg tissues was observed for 13 or 19 amino acids (Fig. 1). Alanine release exceeded that of all other amino acids, accounting for $35-40 \%$ of the measured amino acid output. A small but significant positive $A-V^{1}$ difference was observed for citrulline, serine, cystine, and $\alpha$ aminobutyrate.

To evaluate the interaction between alanine and glucose metabolism, the relation between arterial alanine and arterial pyruvate concentration was examined. As shown in Fig. 2, a significant direct linear correlation was observed $(r=0.606, P<0.005)$. In contrast, no significant correlation with pyruvate was demonstrated for any of the other 18 amino acids $(P$ $>0.1$ ).

The exchange of amino acids across the splanchnic bed was studied in 12 subjects (Fig. 3 ). In agreement with previous observations $(9,16)$, a significant net

\footnotetext{
${ }^{1}$ Abbreviations used in this paper: A-FV, arterio-femoral venous; $\mathrm{A}-\mathrm{HV}$, arterio-hepatic venous; $\mathrm{A}-\mathrm{V}$, arterio-venous.
} 


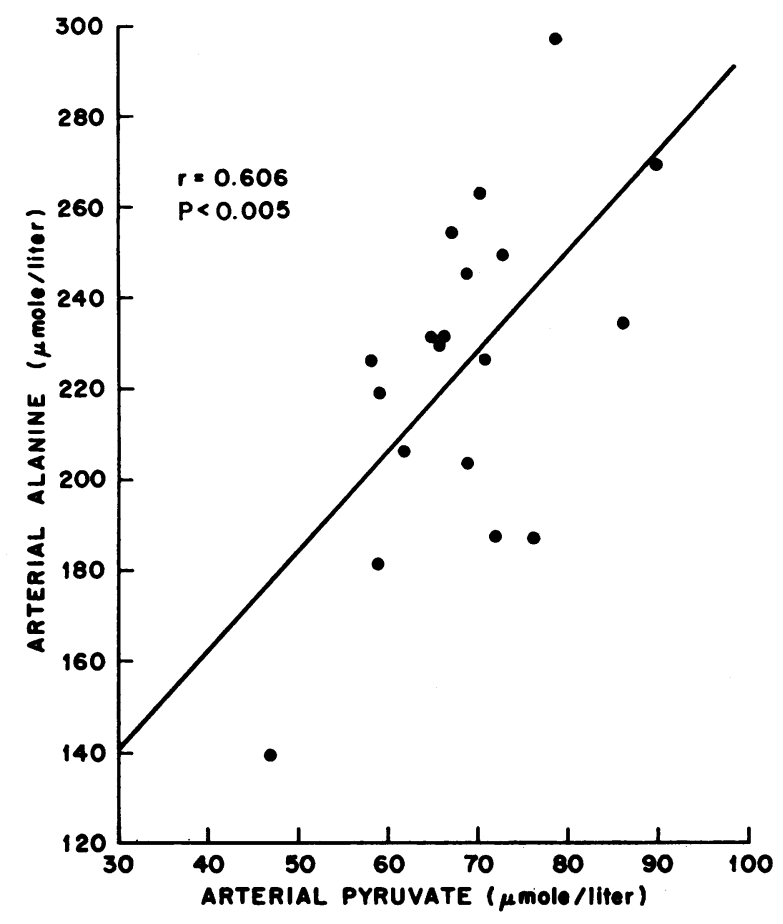

FIGURE 2 Relation of arterial alanine concentration to arterial pyruvate levels in subjects in the resting state.

uptake was demonstrable for 10 amino acids, the extraction of alanine exceeding that of all other amino acids. A net output was observed for citrulline, while for the remaining eight amino acids, splanchnic ex-

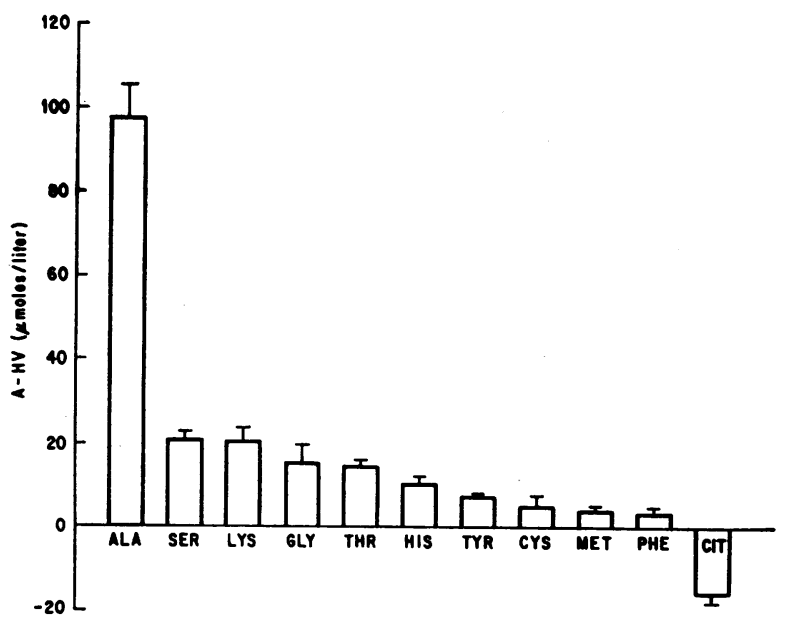

FIGURE 3 Net balance of individual amino acids across the splanchnic bed (arterio-hepatic venous differences, A-HV) in 12 subjects in the resting, postabsorptive state. The lines at the top of the bars represent the standard error of the mean. Only those amino acids whose mean A-HV differences were significantly different from zero are shown. change was too small or variable to result in statistically significant arterio-hepatic venous differences.

The data on the subjects from whom arterial and portal venous blood samples were obtained are shown in Table II. Although the mean levels of virtually all amino acids were higher in portal venous than in arterial blood, consistent net release into the portal circulation was observed only for citrulline, alanine, glycine, leucine, and isoleucine. In no case was there evidence of significant net extraction of amino acids by the tissues drained by the portal vein. The relatively large output of citrulline and alanine is noteworthy.

Response to exercise. As shown in Table I, mild exercise $(400 \mathrm{~kg}-\mathrm{m} / \mathrm{min})$ resulted in a 3 - to 4-fold increase in oxygen consumption. At higher work intensities, oxygen uptake increased 7- to 8-fold (moderate exercise), and 10- to 12-fold (severe exercise) above resting levels. Similar increases were noted in estimated blood flow to the legs (Table I). Heart rate was $61 \pm 3$ (mean $\pm \mathrm{se}$, beats $/ \mathrm{min}$ ) at rest and rose to mean maximal levels of $109 \pm 8,147 \pm 8$, and $160 \pm 3$ during mild, moderate, and severe exercise, respectively.

The effect of exercise on the arterial concentrations of plasma amino acids is shown in Table III. A significant increase in plasma alanine was observed after 10 and $40 \mathrm{~min}$ of exercise at all levels of work intensity. With mild exercise, arterial alanine rose 20

TABLE II

Arterio-Portal Venous Djfferences $(A-P V)$ of Plasma Amino Acids*

\begin{tabular}{lccc}
\hline & Arterial level & A-PV & $P \ddagger$ \\
\hline Taurine & $64.8 \pm 8.68$ & $-3.6 \pm 5.5$ & NS \\
Threonine & $118.4 \pm 13.8$ & $-1.6 \pm 3.6$ & NS \\
Serine & $110.0 \pm 11.0$ & $-2.4 \pm 5.1$ & NS \\
Proline & $147.6 \pm 14.3$ & $-9.8 \pm 5.2$ & NS \\
Citrulline & $26.2 \pm 3.1$ & $-24.8 \pm 5.3$ & $<0.005$ \\
Glycine & $228.6 \pm 14.4$ & $-14.8 \pm 5.9$ & $<0.05$ \\
Alanine & $314.6 \pm 38.3$ & $-33.6 \pm 16.0$ & $<0.05$ \\
$\alpha$-Aminobutyrate & $19.4 \pm 2.8$ & $0.4 \pm 1.7$ & NS \\
Valine & $169.6 \pm 14.1$ & $-3.0 \pm 3.4$ & NS \\
$\frac{1}{2}$ Cystine & $96.0 \pm 4.0$ & $-7.0 \pm 7.5$ & NS \\
Methionine & $15.8 \pm 0.9$ & $-1.8 \pm 1.0$ & NS \\
Isoleucine & $37.2 \pm 3.1$ & $-3.4 \pm 0.9$ & $<0.025$ \\
Leucine & $86.8 \pm 10.3$ & $-7.2 \pm 2.1$ & $<0.025$ \\
Tyrosine & $39.0 \pm 2.9$ & $-1.0 \pm 1.5$ & NS \\
Phenylalanine & $36.4 \pm 3.1$ & $-2.4 \pm 2.1$ & NS \\
& & &
\end{tabular}

* Blood samples were obtained from five subjects at the time of elective cholecystectomy. The basic amino acids were not measured in these subjects.

$\ddagger P=$ probability that A-PV does not differ from zero (paired $t$ test).

$\S$ Mean \pm SE, $\mu$ moles/liter. 
TABLE III

Influence of Exercise at Various Intensities on Arterial Concentrations of Plasma Amino Acids*

\begin{tabular}{|c|c|c|c|c|c|c|c|}
\hline & \multirow[b]{2}{*}{ Rest (n = 19) } & \multicolumn{2}{|c|}{ Mild exercise $(n=9)$} & \multicolumn{2}{|c|}{ Moderate exercise $(n=5)$} & \multicolumn{2}{|c|}{ Severe exercise $(n=5)$} \\
\hline & & $10 \mathrm{~min}$ & $40 \mathrm{~min}$ & $10 \mathrm{~min}$ & $40 \mathrm{~min}$ & $10 \mathrm{~min}$ & $40 \mathrm{~min}$ \\
\hline Taurine & $46.3 \pm 1.5$ & $57.3 \pm 5.0$ & $51.7 \pm 2.9$ & $44.6 \pm 1.2$ & $49.0 \pm 0.7$ & $48.8 \pm 3.4$ & $56.2 \pm 6.0$ \\
\hline Threonine & $111.8 \pm 4.6$ & $103.7 \pm 4.9$ & $102.9 \pm 5.4$ & $124.8 \pm 13.0$ & $130.4 \pm 14.1 \ddagger$ & $113.2 \pm 7.1$ & $115.6 \pm 1.8$ \\
\hline Serine & $119.7 \pm 4.3$ & $116.4 \pm 4.8$ & $114.4 \pm 5.3$ & $111.8 \pm 9.00$ & $118.0 \pm 9.6$ & $112.4 \pm 8.2$ & $110.6 \pm 10.9$ \\
\hline Proline & $156.4 \pm 8.8$ & $148.9 \pm 10.7$ & $141.8 \pm 9.9$ & $160.2 \pm 14.7$ & $159.0 \pm 14.4$ & $197.6 \pm 22.5$ & $198.6 \pm 21.1$ \\
\hline Citrulline & $37.9 \pm 2.0$ & $39.0 \pm 2.8$ & $39.5 \pm 2.0$ & $30.2 \pm 2.0$ & $29.0 \pm 1.5$ & $34.2 \pm 2.8$ & $31.4 \pm 2.0$ \\
\hline Glycine & $213.8 \pm 8.1$ & $217.8 \pm 8.2$ & $220.7 \pm 11.1$ & $208.2 \pm 16.2$ & $220.4 \pm 19.9$ & $204.8 \pm 10.2$ & $212.0 \pm 28.8$ \\
\hline Alanine & $225.0 \pm 8.5$ & $269.2 \pm 19.2 \S$ & $284.9 \pm 22.2 \S$ & $384.4 \pm 24.5 \S$ & $424.4 \pm 30.0 \S$ & $358.4 \pm 28.4 \|$ & $439.8 \pm 34.7 \|$ \\
\hline$\alpha$-Aminobutyrate & $27.4 \pm 2.2$ & $27.6 \pm 3.2$ & $26.4 \pm 2.9$ & $22.0 \pm 3.2$ & $22.2 \pm 2.8$ & $26.2 \pm 2.8$ & $25.8 \pm 2.9$ \\
\hline Valine & $225.8 \pm 5.2$ & $234.7 \pm 8.7$ & $225.3 \pm 7.2$ & $235.4 \pm 12.4$ & $244.0 \pm 14.4$ & $231.6 \pm 15.9$ & $239.4 \pm 12.0$ \\
\hline Cystine & $98.9 \pm 3.7$ & $102.1 \pm 4.5$ & $95.2 \pm 6.4$ & $100.8 \pm 4.2$ & $108.4 \pm 6.5$ & $82.0 \pm 9.0$ & $90.6 \pm 4.9$ \\
\hline Methionine & $17.2 \pm 0.5$ & $17.3 \pm 0.8$ & $18.6 \pm 1.1$ & $19.4 \pm 1.2$ & $23.8 \pm 0.7 \S$ & $19.0 \pm 1.1$ & $24.4 \pm 1.5 \S$ \\
\hline Isoleucine & $53.5 \pm 1.1$ & $55.7 \pm 2.0$ & $55.3 \pm 2.2$ & $54.6 \pm 2.4$ & $57.8 \pm 3.3$ & $58.0 \pm 4.0$ & $61.4 \pm 2.7 \ddagger$ \\
\hline Leucine & $121.2 \pm 3.0$ & $129.9 \pm 5.6$ & $129.7 \pm 4.9$ & $123.6 \pm 5.4$ & $129.8 \pm 7.2 \|$ & $123.2 \pm 5.3$ & $130.4 \pm 3.9 \ddagger$ \\
\hline Tyrosine & $42.8 \pm 1.6$ & $45.3 \pm 3.2$ & $46.9 \pm 2.9$ & $48.0 \pm 4.3$ & $53.0 \pm 3.4 \|$ & $43.2 \pm 3.3$ & $50.6 \pm 1.5 \S$ \\
\hline Phenylalanine & $45.5 \pm 1.4$ & $48.4 \pm 2.2$ & $49.7 \pm 1.5 \|$ & $53.6 \pm 4.7$ & $60.4 \pm 5.5 \|$ & $49.0 \pm 2.6$ & $60.0 \pm 2.0 \$$ \\
\hline Ornithine & $87.2 \pm 4.6$ & - & $78.6 \pm 6.9$ & - & - & - & $75.3 \pm 2.6$ \\
\hline Lysine & $165.3 \pm 9.0$ & - & $169.3 \pm 12.0$ & - & - & - & $166.8 \pm 12.5$ \\
\hline Histidine & $84.3 \pm 2.7$ & - & $83.2 \pm 2.8$ & - & - & 一 & $88.8 \pm 3.9$ \\
\hline Arginine & $48.3 \pm 4.1$ & - & $54.7 \pm 3.3$ & - & - & - & $55.6 \pm 6.0$ \\
\hline
\end{tabular}

* Data are presented as mean $\pm \mathrm{SE}, \mu$ mole/liter. The basic amino acids were not measured in the samples obtained during moderate exercise and after $10 \mathrm{~min}$ of mild and severe exercise.

‡ Significantly different from resting value, $P<0.05$ (paired $t$ test).

$\$$ Significantly different from resting value, $P<0.001$ (paired $t$ test).

|| Significantly different from resting value, $P<0.01$ (paired $t$ test).

$25 \%$, while with more intense exercise, alanine levels increased $60-96 \%$. In contrast, the concentration of all other amino acids was unchanged during light exercise, while increases of $8-35 \%$ were noted for isoleucine, leucine, methionine, tyrosine, and phenylalanine after $40 \mathrm{~min}$ of moderate and severe exercise.

As in the resting state, arterial alanine concentration during exercise was directly proportional to the level of arterial pyruvate (Fig. 4), which also rose in association with physical exertion (Fig. 5). In contrast, a distinct difference was noted between the response of arterial alanine and arterial lactate as the exercise was continued for $40 \mathrm{~min}$. Whereas arterial lactate levels reached a peak within the first 5-10 min of initiation of exercise, after which a significant decline was observed, arterial alanine concentration continued to rise between 10 and $40 \mathrm{~min}$ of exercise (Fig. $5)$.

The influence of exercise on peripheral amino acid exchange is shown in Table IV. After 10 and $40 \mathrm{~min}$ of exercise at all work intensities significant negative arterio-femoral venous differences indicating consistent net release from the leg were observed only in the case of alanine. Although the A-FV differences for alanine were smaller than in the resting state, estimated alanine release from the legs, calculated from the A-FV differences and estimated leg plasma flow (Table I), increased $55 \%$ during mild exercise, $90 \%$ during moderate exercise, and $500 \%$ during severe exercise (Fig. $6)$. For all other amino acids, the A-FV differences (Table IV) were either too small to be significant, or alternatively, small outputs were noted in isolated instances (methionine and serine, moderate exercise, 40 min; proline and threonine, severe exercise, 10 and 40 min, respectively).

In Table $V$ the effect of exercise on estimated hepatic blood flow is shown. In accordance with previous observations (13), hepatic blood flow fell $30 \%$ during mild exercise and $50-60 \%$ in association with the heavier work loads. Splanchnic exchange of plasma amino acids is shown in Table VI. At all work intensities, alanine uptake exceeded that of all other amino acids. The net rate of alanine uptake increased slightly above resting levels during mild and moderate exercise, and did not change significantly with severe exercise. The failure of alanine uptake to decline despite the diminution in hepatic blood flow during exercise, was not solely a consequence of the higher arterial levels, but was due in part to a significantly greater fractional extraction of alanine at the mild and moderate work 


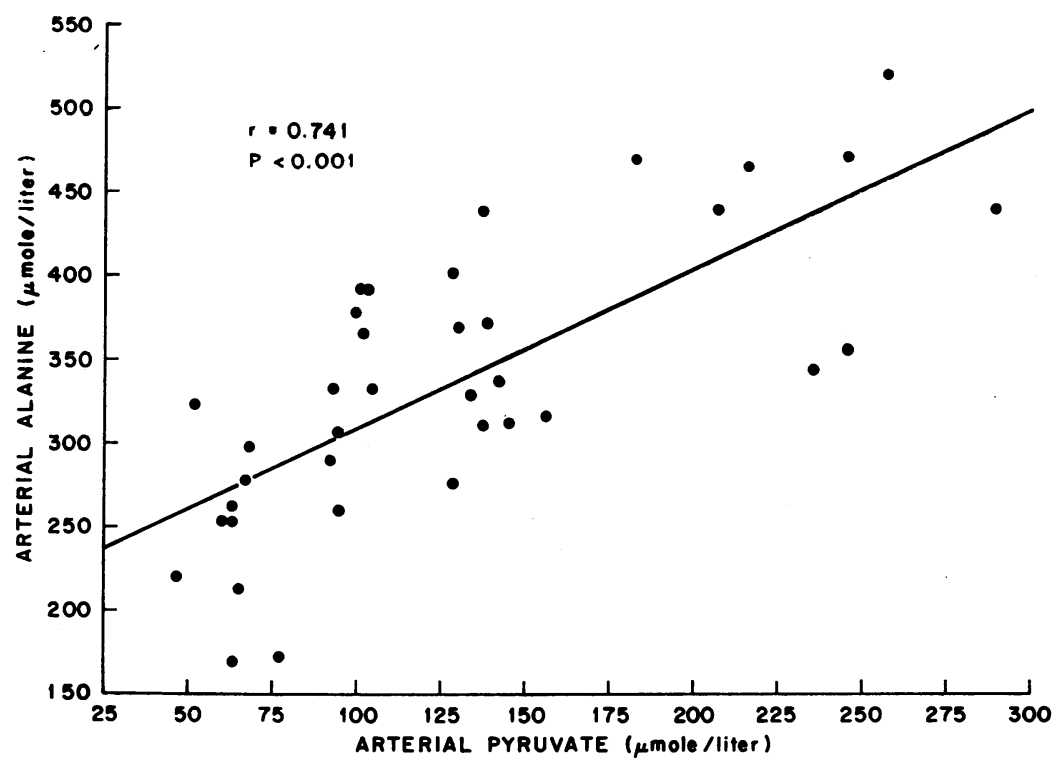

FIGURE 4 Relation of arterial alanine concentration to arterial pyruvate levels during exercise. The values observed after 10 and $40 \mathrm{~min}$ of exercise at all levels of work intensity are shown.

loads (Fig. 7). A significant decrease in splanchnic uptake was observed for serine, tyrosine, and phenylalanine during severe exercise. In the case of the branchedchain amino acids (valine, leucine, and isoleucine), for which no consistent splanchnic uptake or release was demonstrable in the resting state, small but significant net outputs were observed after $40 \mathrm{~min}$ of severe exercise (Table VI).

The changes in arterial alanine concentration and in peripheral and splanchnic alanine exchange in a representative subject during moderate exericse are summarized in Fig. 8.

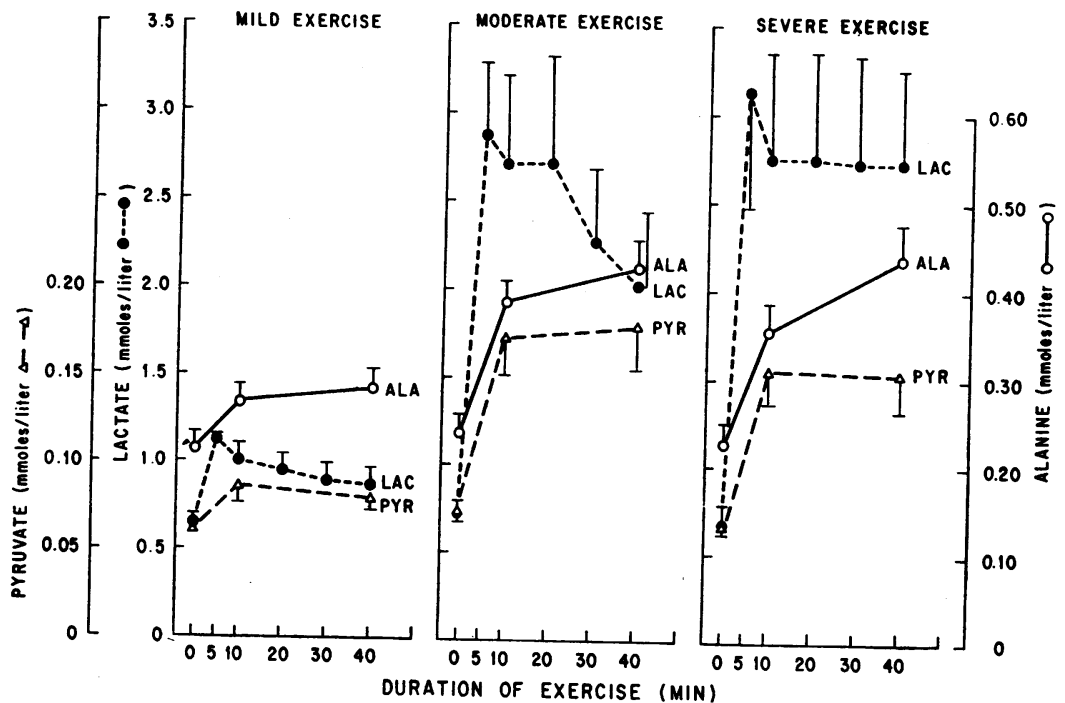

FIGURE 5 Comparison of response of arterial pyruvate (PYR), lactate (LAC), and alanine (ALA) to $40 \mathrm{~min}$ of exercise at various work intensities. The vertical lines represent the standard error of the mean. The increase in arterial alanine concentration between 10 and $40 \mathrm{~min}$ of exercise was significant in the moderate and severe exercise groups $(P<0.025$, paired $t$ test $)$. In contrast, arterial lactate levels fell significantly between 5 and 10 and 40 min of exercise at each work load $(P<0.05$, paired $t$ test $)$. 
TABLE IV

Arierio-Femoral Venous Differences of Plasma Amino Acids in Subjects at Rest and after 10 and 40 min of Exercise at Various Work Intensities*

\begin{tabular}{|c|c|c|c|c|c|c|c|}
\hline & \multirow[b]{2}{*}{ Rest $(n=19)$} & \multicolumn{2}{|c|}{ Mild exercise $(n=9)$} & \multicolumn{2}{|c|}{ Moderate exercise $(n=5)$} & \multicolumn{2}{|c|}{ Severe exercise $(n=5)$} \\
\hline & & $10 \mathrm{~min}$ & $40 \mathrm{~min}$ & $10 \mathrm{~min}$ & $40 \mathrm{~min}$ & $10 \mathrm{~min}$ & $40 \mathrm{~min}$ \\
\hline Taurine & $1.2 \pm 1.4$ & $-2.7 \pm 3.4$ & $-0.3 \pm 1.7$ & $-2.6 \pm 3.5$ & $2.2 \pm 1.6$ & $0.2 \pm 2.6$ & $3.8 \pm 4.8$ \\
\hline Threonine & $-11.4 \pm 0.9 \ddagger$ & $-0.5 \pm 1.3$ & $0.1 \pm 2.1$ & $-4.2 \pm 2.0$ & $2.2 \pm 0.98$ & $-2.6 \pm 8.9$ & $-3.5 \pm 1.08$ \\
\hline Serine & $9.9 \pm 4.48$ & $6.3 \pm 2.48$ & $4.4 \pm 2.08$ & $-2.2 \pm 1.9$ & $-2.0 \pm 0.68$ & $-1.0 \pm 9.3$ & $-6.0 \pm 5.9$ \\
\hline Proline & $-15.9 \pm 4.0 \ddagger$ & $-5.0 \pm 2.8$ & $1.4 \pm 2.5$ & $-4.6 \pm 5.8$ & $-5.4 \pm 4.5$ & $-14.2 \pm 5.0 \S$ & $6.3 \pm 5.0$ \\
\hline Citrulline & $4.1 \pm 0.8 \ddagger$ & $0.3 \pm 1.5$ & $1.5 \pm 2.3$ & $0.4 \pm 1.2$ & $0.8 \pm 0.9$ & $-0.8 \pm 2.3$ & $-1.8 \pm 1.0$ \\
\hline Glycine & $-23.1 \pm 3.5 \ddagger$ & $-9.0 \pm 9.3$ & $1.4 \pm 6.9$ & $-9.0 \pm 6.3$ & $-8.6 \pm 13.9$ & $-15.6 \pm 9.4$ & $8.3 \pm 15.0$ \\
\hline Alanine & $-67.9 \pm 6.0 \ddagger$ & $-24.8 \pm 5.5 \|$ & $-20.3 \pm 3.0 \ddagger$ & $-24.6 \pm 10.68$ & $-19.0 \pm 5.0 \|$ & $-36.2 \pm 15.5 \S$ & $-28.5 \pm 8.9 \S$ \\
\hline$\alpha$-Aminobutyrate & $1.5 \pm 0.5 \|$ & $2.3 \pm 1.08$ & $0.9 \pm 0.8$ & $-1.0 \pm 3.2$ & $1.4 \pm 0.8$ & $-3.6 \pm 3.0$ & $0.8 \pm 1.3$ \\
\hline Valine & $-7.8 \pm 3.48$ & $2.2 \pm 3.3$ & $4.4 \pm 3.8$ & $-4.0 \pm 5.6$ & $2.4 \pm 2.9$ & $-11.4 \pm 7.3$ & $0.8 \pm 2.3$ \\
\hline Cystine & $8.2 \pm 1.8 \ddagger$ & $7.0 \pm 1.8 \|$ & $2.9 \pm 3.5$ & $-3.3 \pm 2.9$ & $0.0 \pm 3.3$ & $-2.8 \pm 7.0$ & $0.3 \pm 3.5$ \\
\hline Methionine & $-3.3 \pm 0.3 \ddagger$ & $-1.4 \pm 0.8$ & $-1.7 \pm 0.88$ & $-2.0 \pm 1.1$ & $0.4 \pm 1.0$ & $-2.7 \pm 1.4$ & $-0.3 \pm 1.8$ \\
\hline Isoleucine & $-2.9 \pm 0.4 \ddagger$ & $-1.4 \pm 0.9$ & $1.1 \pm 1.7$ & $-2.8 \pm 2.4$ & $0.2 \pm 0.6$ & $-4.6 \pm 3.2$ & $-1.3 \pm 1.3$ \\
\hline Leucine & $-8.9 \pm 2.2 \ddagger$ & $-2.4 \pm 1.8$ & $2.3 \pm 2.6$ & $-3.8 \pm 3.1$ & $1.0 \pm 1.3$ & $-9.6 \pm 6.1$ & $-4.8 \pm 4.9$ \\
\hline Tyrosine & $-3.5 \pm 0.5 \ddagger$ & $-1.0 \pm 1.1$ & $0.4 \pm 1.3$ & $-1.6 \pm 1.4$ & $-0.6 \pm 0.8$ & $-1.0 \pm 2.2$ & $1.5 \pm 0.9$ \\
\hline Phenylalanine & $-4.7 \pm 0.5 t$ & $0.0 \pm 1.3$ & $0.3 \pm 1.3$ & $-2.2 \pm 1.5$ & $0.0 \pm 0.7$ & $-3.8 \pm 2.6$ & $1.3 \pm 1.6$ \\
\hline Ornithine & $1.6 \pm 3.4$ & - & $3.4 \pm 1.6$ & - & - & - & $2.3 \pm 1.7$ \\
\hline Lysine & $-19.0 \pm 3.9 \ddagger$ & 一 & $-4.9 \pm 9.1$ & - & - & - & $6.0 \pm 7.0$ \\
\hline Histidine & $-9.2 \pm 1.9 \ddagger$ & - & $-1.1 \pm 3.2$ & - & - & - & $15.8 \pm 16.5$ \\
\hline Arginine & $-6.4 \pm 2.1 \|$ & - & $-3.4 \pm 3.0$ & - & - & - & $1.5 \pm 2.5$ \\
\hline
\end{tabular}

* Data presented as mean $\pm \mathrm{SE}, \mu$ mole/liter. The basic amino acids were not measured in the samples obtained during moderate exercise, and after 10 min of mild and severe exercise.

† Significantly different from zero, $P<0.001$.

Significantly different from zero, $P<0.05$.

II Significantly different from zero, $P<0.01$.

\section{DISCUSSION}

The current data provide further evidence of the unique role of alanine in peripheral and splanchnic amino acid metabolism. The primacy of alanine in amino acid outflow from peripheral protein depots is indicated by the fact that the A-V difference for alanine across the leg in the resting state, as in the case of the forearm $(6,7)$, is far in excess of that of other amino acids.

During exercise the special role of alanine is further accentuated. In agreement with previous observations in four subjects by Carlsten, Hällgren, Jagenburg, Svanborg, and Werkö (20), alanine is the only amino acid to increase in arterial concentration during light exercise and to demonstrate a twofold increment with more severe exertion. It is also the only amino acid for which a consistent output is demonstrable from the exercising leg. In this respect, exercising skeletal muscle is comparable with cardiac muscle which also releases only alanine (21). Furthermore, the estimated rate of alanine output from muscle increases markedly during exercise and in proportion to the level of physical activity. Since there is no evidence of a specific alanine-rich protein in muscle (8), the current findings support the conclusion that alanine release during exercise, as well as in the resting state, is not solely dependent on protein dissolution but is determined, at least in part, by the rate of peripheral alanine synthesis, presumably by transamination of pyruvate. The inter- dependence of alanine and pyruvate metabolism is further suggested by the significant direct linear correlation between arterial alanine and pyruvate levels. In addition, hyperalaninemia in the absence of generalized hyperaminoacidemia has recently been reported in children with thiamine-dependent hyperpyruvicemia (22, 23 ). The carbon skeleton of alanine thus may constitute an important end product of glycolysis, particu-
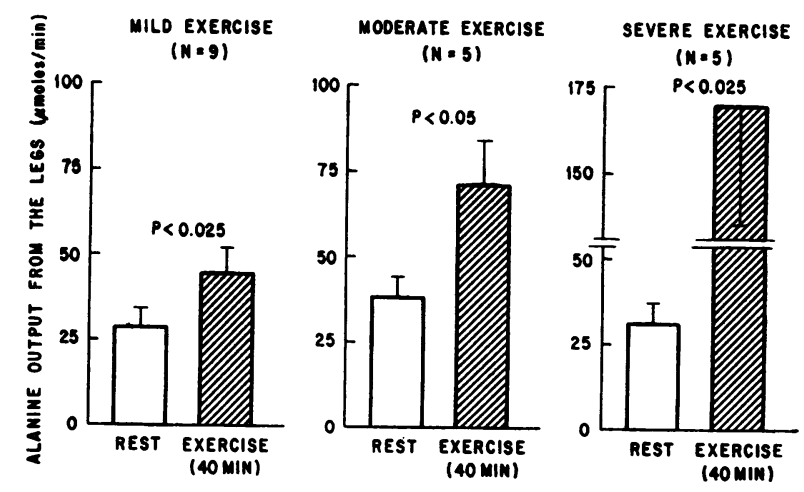

FIGURE 6 Influence of $40 \mathrm{~min}$ of exercise at various work intensities on estimated alanine output from the legs. Alanine output was calculated as the product of the arterio-femoral venous difference for alanine (Table IV) and the estimated plasma flow to the legs (Table I). The lines at the top of the bars represent the standard error of the mean. $P$ values indicate the significance of the change from resting state (paired $t$ test). 
TABLE V

Hepatic Blood Flow during Exercise at Various Work Intensities*

\begin{tabular}{|c|c|c|c|c|c|c|c|c|c|}
\hline \multirow[b]{2}{*}{ Work intensity } & \multirow[b]{2}{*}{ Rest } & \multicolumn{8}{|c|}{ Duration of exercise in minutes } \\
\hline & & 5 & 10 & 15 & 20 & 25 & 30 & 35 & 40 \\
\hline & \multicolumn{9}{|c|}{$m l / m i n$} \\
\hline \multicolumn{10}{|l|}{ Mild exercise } \\
\hline$(n=4)$ & $1075 \pm 44$ & $931 \pm 67$ & $945 \pm 90$ & $866 \pm 111$ & $843 \pm 116$ & $745 \pm 103$ & $730 \pm 109$ & $720 \pm 111$ & $747 \pm 136$ \\
\hline Moderate exercise & & & & & & & & & \\
\hline$(n=4)$ & $1200 \pm 144$ & $671 \pm 88$ & $631 \pm 82$ & $715 \pm 103$ & $637 \pm 89$ & $643 \pm 101$ & $547 \pm 92$ & $550 \pm 72$ & $537 \pm 57$ \\
\hline \multicolumn{10}{|l|}{ Severe exercise } \\
\hline$(n=4)$ & $1144 \pm 65$ & $665 \pm 40$ & $585 \pm 16$ & $484 \pm 35$ & $476 \pm 32$ & $485 \pm 63$ & $466 \pm 48$ & $486 \pm 57$ & $434 \pm 37$ \\
\hline
\end{tabular}

* Data presented as mean $\pm \mathrm{SE}$.

larly in exercise. Supporting this conclusion is the observation that a significant proportion of muscle glycogen dissipation and glucose utilization in exercise cannot be accounted for by lactate formation or $\mathrm{CO}_{2}$ production (24).

While the proportion of total glucose uptake by muscle which may be accounted for by alanine production has not been determined directly, some estimates may be made from the available data (Table VII). Since lysine does not undergo reversible transamination, its peripheral release provides an approximate index of muscle proteolysis (25). In addition, alanine concentration in muscle protein is virtually identical with that of lysine (8). Thus the extent to which alanine output exceeds that of lysine may reflect the proportion of alanine derived from glucose. On this basis, 13 and $18 \%$ of glucose uptake by the leg and deep tissues of the forearm, respectively, may be accounted for by alanine production (Table VII). The higher estimate in forearm is to be expected, since the deep vein of the forearm drains primarily muscle (7), while the femoral vein includes drainage from subcutaneous fat, in which significant alanine formation and release would not be anticipated.

TABLE VI

Influence of Exercise at Various Intensities on Splanchnic Exchange of Plasma Amino Acids*

\begin{tabular}{|c|c|c|c|c|c|c|c|}
\hline & \multirow[b]{2}{*}{ Rest $(n=12)$} & \multicolumn{2}{|c|}{ Mild exercise $(n=4)$} & \multicolumn{2}{|c|}{ Moderate exercise $(n=4)$} & \multicolumn{2}{|c|}{ Severe exercise $(n=4)$} \\
\hline & & $10 \mathrm{~min}$ & $40 \mathrm{~min}$ & $10 \mathrm{~min}$ & $40 \mathrm{~min}$ & $10 \mathrm{~min}$ & $40 \mathrm{~min}$ \\
\hline Taurine & $2.3 \pm 1.8$ & $2.8 \pm 1.4$ & $0.8 \pm 1.0$ & $0.7 \pm 0.3$ & $0.6 \pm 0.4$ & $2.2 \pm 0.8$ & $1.9 \pm 1.8$ \\
\hline Threonine & $9.7 \pm 1.2$ & $8.5 \pm 3.4$ & $11.1 \pm 3.4$ & $6.2 \pm 0.6 \ddagger$ & $10.6 \pm 2.3$ & $10.1 \pm 4.8$ & $7.9 \pm 1.7$ \\
\hline Serine & $13.4 \pm 1.5$ & $11.1 \pm 3.5$ & $12.9 \pm 2.6$ & $7.6 \pm 1.1 \ddagger$ & $8.9 \pm 2.2 \ddagger$ & $9.7 \pm 4.1$ & $4.1 \pm 0.5 \S$ \\
\hline Proline & $0.5 \pm 2.1$ & $-2.3 \pm 2.8$ & $5.5 \pm 1.1$ & $1.3 \pm 2.1$ & $2.0 \pm 3.2$ & $9.2 \pm 7.7$ & $7.8 \pm 4.6$ \\
\hline Citrulline & $-10.5 \pm 1.2$ & $-9.7 \pm 2.0$ & $-7.2 \pm 2.3$ & $-8.6 \pm 0.9$ & $-8.6 \pm 2.8$ & $-6.2 \pm 1.7$ & $-5.7 \pm 3.0$ \\
\hline Glycine & $10.7 \pm 3.5$ & $8.3 \pm 4.2$ & $15.8 \pm 10.7$ & $4.9 \pm 2.5$ & $8.6 \pm 4.6$ & $1.3 \pm 0.7$ & $13.5 \pm 7.4$ \\
\hline Alanine & $64.8 \pm 6.6$ & $58.5 \pm 7.0$ & $76.6 \pm 9.7 \ddagger$ & $56.9 \pm 12.5$ & $76.5 \pm 9.9 \ddagger$ & $47.7 \pm 13.4$ & $56.7 \pm 16.8$ \\
\hline$\alpha$-Aminobutyrate & $-1.7 \pm 1.9$ & $0.2 \pm 0.8$ & $0.3 \pm 0.6$ & $-0.6 \pm 0.4$ & $-1.4 \pm 0.4$ & $-0.2 \pm 0.6$ & $-0.1 \pm 0.5$ \\
\hline Valine & $0.4 \pm 2.1$ & $5.4 \pm 7.4$ & $-1.9 \pm 2.7$ & $0.2 \pm 1.1$ & $-1.3 \pm 3.0$ & $-3.5 \pm 4.3$ & $-5.4 \pm 2.08$ \\
\hline Cystine & $3.2 \pm 1.5$ & $1.3 \pm 1.4$ & $0.3 \pm 2.2$ & $-1.3 \pm 1.5$ & $0.7 \pm 3.0$ & $-2.3 \pm 0.6$ & $-1.8 \pm 1.4$ \\
\hline Methionine & $2.9 \pm 0.4$ & $2.8 \pm 0.8$ & $3.1 \pm 0.9$ & $2.2 \pm 0.3$ & $3.0 \pm 0.3$ & $2.4 \pm 0.6$ & $2.3 \pm 0.6$ \\
\hline Isoleucine & $-0.4 \pm 0.9$ & $0.1 \pm 1.5$ & $-1.8 \pm 1.6$ & $0.6 \pm 0.5$ & $-1.1 \pm 1.1$ & $-0.8 \pm 2.5$ & $-3.3 \pm 1.38$ \\
\hline Leucine & $-0.5 \pm 1.2$ & $-3.1 \pm 1.9$ & $-1.6 \pm 2.4$ & $0.6 \pm 0.7$ & $-4.4 \pm 3.6$ & $-3.7 \pm 3.8$ & $-7.7 \pm 2.4 \ddagger$ \\
\hline Tyrosine & $5.0 \pm 0.4$ & $3.7 \pm 1.4$ & $5.3 \pm 1.9$ & $3.4 \pm 0.8$ & $3.7 \pm 1.0$ & $4.1 \pm 1.6$ & $1.7 \pm 0.48$ \\
\hline Phenylalanine & $2.6 \pm 0.7$ & $3.1 \pm 1.4$ & $3.5 \pm 1.2$ & $2.3 \pm 0.8$ & $3.2 \pm 1.1$ & $2.3 \pm 1.7$ & $1.1 \pm 0.6 \ddagger$ \\
\hline Ornithine & $6.3 \pm 4.0$ & - & $7.6 \pm 4.9$ & - & - & - & $2.3 \pm 6.7$ \\
\hline Lysine & $12.8 \pm 2.9$ & - & $13.4 \pm 6.8$ & - & - & 一 & $9.5 \pm 1.6$ \\
\hline Histidine & $6.7 \pm 1.9$ & - & $7.8 \pm 3.2$ & - & - & - & $2.3 \pm 0.9$ \\
\hline Arginine & $4.4 \pm 3.8$ & - & $5.0 \pm 4.2$ & 一 & - & - & $8.4 \pm 4.5$ \\
\hline
\end{tabular}

* Data are presented as mean $\pm \mathrm{SE}, \mu \mathrm{moles} / \mathrm{min}$. Splanchnic uptake was calculated from arterio-hepatic venous differences and splanchnic plasma flow.

¥ Significantly different from resting value, $P<0.05$ (paired $t$ test).

Significantly different from resting value, $P<0.01$ (paired $t$ test). 
As to the mechanism of the increase in alanine release during exercise, the marked augmentation in glucose uptake by the leg (2), and the elevation in arterial pyruvate levels, provide evidence of increased availability of pyruvate for transamination. An increase in muscle transaminase activity has also been observed in exercise. ${ }^{2}$ With respect to the source of the amino groups necessary for alanine formation, it has been demonstrated that the branched-chain amino acids are preferentially catabolized in muscle rather than liver $(26,27)$. An additional source of amino groups, particularly during exercise, is likely to be aspartate. Increased formation of oxaloacetate from aspartate has been observed in association with augmented activity of the tricarboxylic acid cycle $(28,29)$. In addition exercise results in a cyclic interconversion of purine nucleotides which is accompanied by conversion of aspartate to fumarate and liberation of ammonia (30). Accordingly, the flow of amino groups and pyruvate in muscle tissue is likely to be augmented in exercise and to enhance thereby peripheral synthesis of alanine and its release into the general circulation.

The functional significance ascribed to peripheral alanine formation with respect to overall body nitrogen metabolism is that it provides a nontoxic alternative to ammonia for the transport of amino groups from muscle to the liver (31). The present demonstration of hyperalaninemia in exercise supports this hypothesis since it is well established that muscular work is associated with augmented peripheral ammonia release (4, 5 ) and generalized hyperammonemia (5). The binding of amino groups by pyruvate to form alanine thus serves to limit the extent to which ammonia production and accumulation are stimulated by exercise. The importance of this carrier function of alanine in nitrogen

${ }^{2}$ Molé, P. A., K. Baldwin, R. Terjung, and J. O. Holloszy. Personal communication.
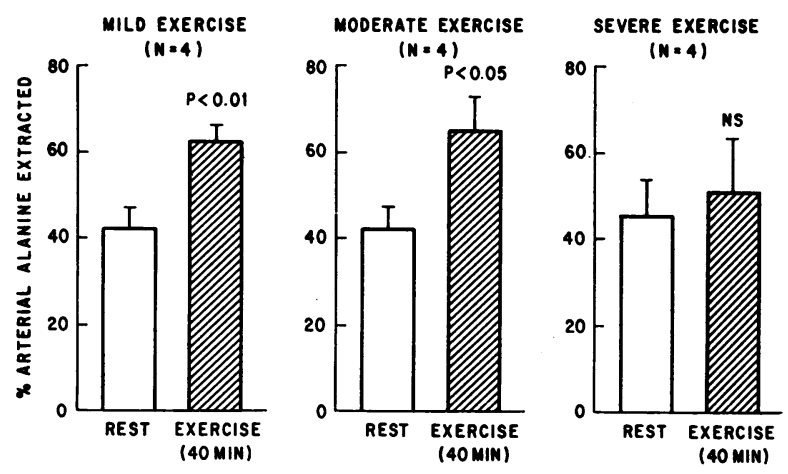

Figure 7 Fractional extraction of alanine by the splanchnic bed at rest and after $40 \mathrm{~min}$ of exercise at various work intensities. The lines at the top of the bars represent the standard error of the mean. $P$ values indicate the significance of the change from resting state (paired $t$ test).

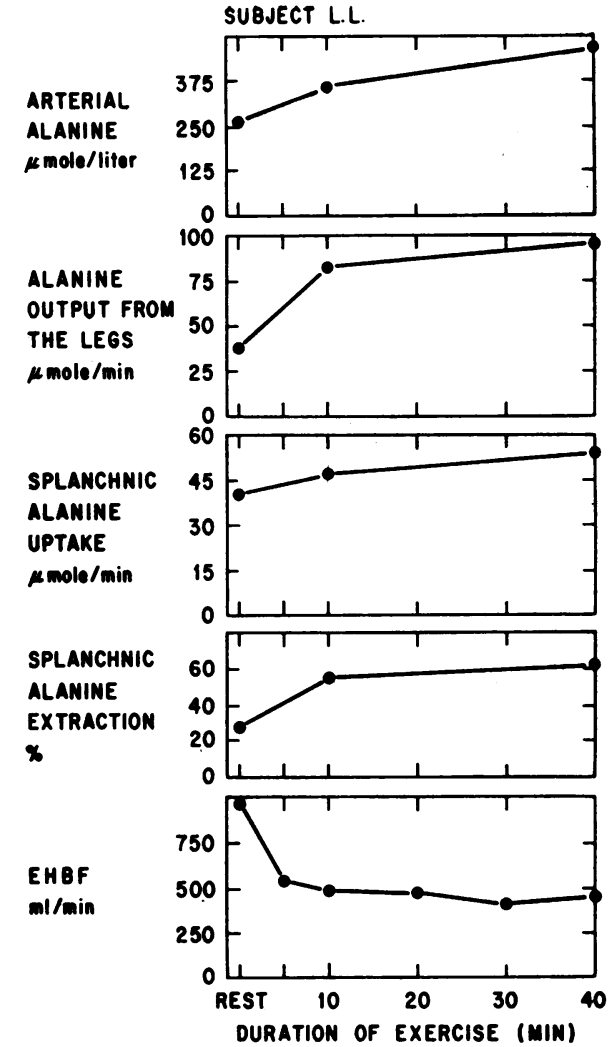

FIGURE 8 Arterial concentration, peripheral output, and splanchnic uptake of alanine in subject L. L. at rest and during moderate $(800 \mathrm{~kg}-\mathrm{m} / \mathrm{min}$ ) exercise. (EHBF = estimated hepatic blood flow.)

metabolism is further indicated by the specific elevation of plasma alanine in a variety of hyperammonemic situations in which ammonia disposal is retarded (32), particularly as a consequence of abnormalities involving urea cycle enzymes (33-35). In addition, alanine serves as an intrahepatic ammonia-binding agent when urea synthesis ceases in the anoxic liver (36).

The possibility may also be entertained that alanine formation represents an alternative mechanism to lactate synthesis for regeneration of oxidized pyridine nucleotides. Since glutamate is formed in part by the reductive amination of $\alpha$-ketoglutarate and may subsequently undergo transamination with pyruvate, each mole of alanine thus formed will be accompanied by the net conversion of 1 mole of NADH to NAD (36). It is noteworthy in this respect that an increase in the plasma alanine: pyruvate $(\mathrm{A}: \mathrm{P})$ ratio has been observed in some patients with severe lactic acidosis (37). However, such an increase was not observed in asso. ciation with exercise in the current study (A: $P$ ratio $3.3 \pm 0.1$ at rest and $3.0 \pm 0.2$ during exercise, mean $\pm \mathrm{sE}$, based on the data in Fig. 2 and 4). Moreover, arterial lactate and alanine differed distinctly in the 


\section{TABLE VII}

Estimation of the Proportion of Leg and Forearm Muscle Glucose Uptake Accounted for by Alanine Production $(A / G)$ in the Resting State

Leg

A-FVGlucose $* 184 \mu$ mole $/$ liter

A-FVAlanine $=-68 \mu \mathrm{mole} /$ liter

A-FVLysine $=-19 \mu$ mole/liter

A-FV"Glucose-derived Alanine" $\ddagger=-49 \mu$ mole/liter

$\mathrm{A} / \mathrm{G} \$=13 \%$

Forearm muscle\|

A-DVGlucose $\mathbb{T}=211 \mu \mathrm{mole} /$ liter

A-DVAlanine $=-111 \mu \mathrm{mole} / \mathrm{liter}$

A-DVLysine $=-37 \mu$ mole $/$ liter

A-DV "Glucose-derived Alanine" $\ddagger=-74 \mu$ mole/liter

$\mathrm{A} / \mathrm{G} \S=18 \%$

* Leg glucose data are based on the observations of Wahren, Felig, Ahlborg, and Jorfeldt (2).

$\ddagger \mathrm{A}-\mathrm{V}$ "Glucose-derived Alanine" = $(\mathrm{A}-\mathrm{V})$ Alanine - $(\mathrm{A}-\mathrm{V})$ Lysine.

$\S \mathrm{A} / \mathrm{G}=100$ ( $\frac{1}{2}$ "glucose-derived alanine" $\mathrm{V}$-A difference)/ (Glucose A-V difference).

|| The data for the forearm are based on the report of Felig, Pozefsky, Marliss, and Cahill (6).

I $\mathrm{A}-\mathrm{DV}=$ Arterio-deep venous difference.

direction of their respective responses to prolonged exercise (Fig. 6).

The importance of alanine as a gluconeogenic substrate has been previously emphasized on the basis of arterio-hepatic venous differences in postabsorptive and fasting man (9). However, net splanchnic balances determined by the hepatic venous catheter technique do not exclude the possibility of extrahepatic alanine uptake by tissues drained by the portal vein which lack the enzymatic capacity for gluconeogenesis. The current demonstration that portal vein alanine levels are slightly but consistently in excess of arterial concentrations indicates that in the postabsorptive state $(a)$ net uptake of alanine is not taking place across the extrahepatic tissues of the splanchnic bed, and $(b)$ net splanchnic alanine uptake slightly underestimates (rather than overestimates) net uptake of alanine by the liver.

The data on splanchnic amino acid exchange during exercise reveal that at all levels of work intensity the carbon skeleton of alanine not only serves as a glycolytic end product but also as an important endogenous precursor for hepatic glucose production. The current findings, based on simultaneous examination of peripheral and splanchnic amino acid exchange, thus provide strong support for the existence of a glucose-alanine cycle involving muscle and liver (Fig. 9). By this formulation alanine is synthesized in muscle from glucose-derived pyruvate and released into the bloodstream.
Circulating alanine is subsequently taken up by the liver where its carbon skeleton is reconverted to glucose. Such a cycle has been previously inferred on the basis of forearm studies in intact man (6) and perfusion studies of rat liver (11). Exercise influences this cyclic interconversion by increasing the rate of muscle alanine formation in excess of the rate of alanine uptake by the liver. As a consequence alanine accumulates in arterial blood (Fig. 9).

Although a 15-20\% increase in splanchnic alanine uptake was observed with the mild and moderate work loads, previous studies (38) have failed to demonstrate an elevation in urine nitrogen excretion which would be anticipated if gluconeogenesis were increasing in association with exercise. This seeming discrepancy is resolved by the fact that while alanine uptake is increasing, splanchnic extraction of other glycogenic amino acids (serine, threonine, tyrosine) is declining (Table VI). Thus, net uptake ot total glycogenic substrate undergoes little change in exercise.

In addition to the elevation in arterial alanine concentration, increases of $8-35 \%$ were noted for isoleucine, leucine, methionine, tyrosine, and phenylalanine after $40 \mathrm{~min}$ of moderate and severe exercise. The interaction of peripheral and splanchnic exchange in effecting these alterations in arterial amino acid concentration is noteworthy. Although consistent outputs from the leg were not observed for any of these amino acids during exercise, a significant decline in the splanchnic uptake of tyrosine and phenylalanine was demonstrated at the heavier work loads. In addition, whereas isoleucine and leucine were neither con-

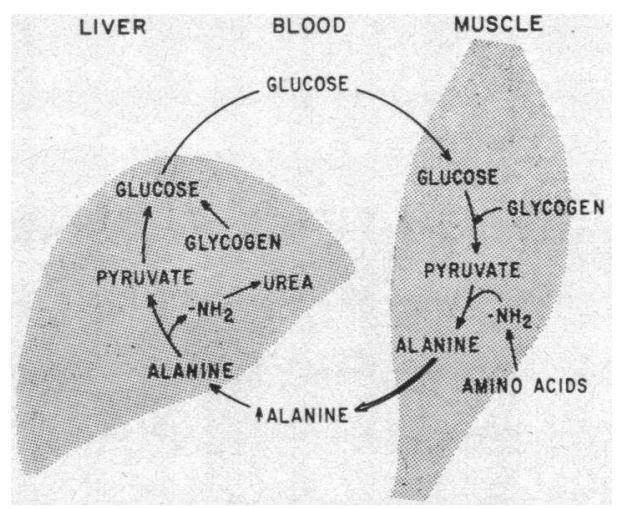

FIGURE 9 The glucose-alanine cycle in exercise. In the resting state, alanine, synthesized in muscle by transamination of glucose-derived pyruvate, serves to convey carbon skeletons and amino groups to the liver, where the latter are converted to urea and the former are reconverted to glucose. During exercise the increased availability of pyruvate and amino groups in muscle results in augmented peripheral synthesis and greater release of alanine into the circulation. Alanine accumulates in arterial blood because the increase in peripheral release exceeds the rate of hepatic uptake. 
sistently extracted nor released by the splanchnic bed in the resting state, significant splanchnic outputs were observed during severe exercise (Table VI). Thus in contrast to alanine, changes in the direction and magnitude of the net splanchnic balance of these specific amino acids were responsible for the elevations in their arterial concentration.

It should be emphasized that accurate measurements of glutamine and glutamate were not possible by the column chromatographic technique employed in the current study (39). Peripheral formation of glutamine and its uptake by the liver have recently been demonstrated in intact man (25). An increase in arterial glutamine levels however has not been observed during exercise (40). In addition, at maximal work loads no significant output of glutamine is demonstrable from the leg (41). Thus while it is likely that in the resting condition, glutamine shares with alanine an important role in the transfer of ammonia from muscle to the liver, during exercise alanine formation would appear to be of greater importance.

\section{ACKNOWLEDGMENTS}

We thank Thomas Trzaski, Donna Murray, Rosa Koff, AnnMari Neuschütz, and Soile Reilo for their expert technical assistance.

This work was supported by U. S. Public Health Service Grant AM-13526 and by a grant from the Swedish Medical Research Council (B71-19 X-3108-01).

\section{REFERENCES}

1. Felig, P., and J. Wahren. 1971. Interrelationship between amino acid and carbohydrate metabolism during exercise: the glucose-alanine cycle. In Muscle Metabolism During Exercise. Proceedings of a Karolinska Institutet symposium held in Stockholm, 19;0. B. Pernow and B. Saltin, editors. Plenum Publishing Corporation, New York, 205.

2. Wahren, J., P. Felig, G. Ahlborg, and L. Jorfeldt. 1971. Glucose metabolism during leg exercise in man. J. Clin. Invest. 50: 2715.

3. Havel, R. J., B. Pernow, and N. L. Jones, 1967. Uptake and release of free fatty acids and other metabolites in the legs of exercising men. J. Appl. Physiol. 23: 90.

4. Parnas, J. K., W. Mozolowski, and W. Lewinski. 1927. Über den Ammoniakgehalt und die Ammoniakbildung im Blute. IX. Der Zusammenhang des Blutammoniaks mit der Muskelarbeit. Biochem. Z. 188: 15.

5. Schwartz, A. E., W. Lawrence, Jr., and K. E. Roberts. 1958. Elevation of peripheral blood ammonia following muscular exercise. Proc. Soc. Exp. Biol. Med. 98: 548.

6. Felig, P., T. Pozefsky, E. Marliss, and G. F. Cahill, Jr. 1970. Alanine: key role in gluconeogenesis. Science (Washington). $167: 1003$.

7. Pozefsky, T., P. Felig, J. D. Tobin, J. S. Soeldner, and G. F. Cahill, Jr. 1969. Amino acid balance across tissues of the forearm in postabsorptive man. Effects of insulin at two dose levels. J. Clin. Invest. 48: 2273.
8. Kominz, D. R., A. Hough, P. Symonds, and K. Laki. 1954. The amino acid composition of actin, myosin, tropomyosin and the meromyosins. Arch. Biochem. Biophys. 50: 148.

9. Felig, P., O. E. Owen, J. Wahren, and G. F. Cahill, Jr. 1969. Amino acid metabolism during prolonged starvation. J. Clin. Invest. 48: 584.

10. Ross, B. D., R. Hems, and H. A. Krebs. 1967. The rate of gluconeogenesis from various precursors in the perfused rat liver. Biochem. J. 102: 942.

11. Mallette, L. E., J. H. Exton, and C. R. Park. 1969. Control of gluconeogenesis from amino acids in the perfused rat liver. J. Biol. Chem. 244: 5713 .

12. Bradley, S. E. 1948. Measurement of hepatic blood flow. Methods Med. Res. 1: 199.

13. Rowell, L. B., K. K. Kraning II, T. O. Evans, J. W. Kennedy, J. R. Blackmon, and F. Kusumi. 1966. Splanchnic removal of lactate and pyruvate during prolonged exercise in man. J. Appl. Physiol. 21: 1773.

14. Bradley, S. E. 1946. Liver function as studied by hepatic vein catheterization. In Transactions of the Fifth Conference on Liver Injury. Josiah Macy Jr. Foundation, New York. 38.

15. Jorfeldt, L., and J. Wahren. 1971. Leg blood flow during exercise in man. Clin. Sci. (London). In press.

16. Felig, P., and J. Wahren. 1971. Influence of endogenous insulin secretion on splanchnic glucose and amino acid metabolism in man. J. Clin. Invest. 50: 1702.

17. Drabkin, D. L. 1950. Measurement of oxygen saturation of blood by direct spectrophotometric determination. Methods Med. Res. V. R. Potter, editor. Year Book Medical Publishers, Inc., Chicago. 2: 159.

18. Drabkin, D. L., and J. H. Austin. 1935. Spectrophotometric studies. II. Preparations from washed blood cells: nitric oxide hemoglobin and sulfhemoglobin. $J$. Biol. Chem. 112: 51.

19. Snedecor, G. W. 1956. Statistical Methods Applied to Experiments in Agriculture and Biology. Iowa State University Press, Ames. 5th edition. 35.

20. Carlsten, A., B. Hallgren, R. Jagenburg, A. Svanborg, and L. Werkö. 1962. Arterial concentrations of free fatty acids and free amino acids in healthy human individuals at rest and at different work loads. Scand. J. Clin. Lab. Invest. 14: 185.

21. Carlsten, A., B. Hallgren, R. Jagenburg, A. Svanborg, and L. Werkö. 1961. Myocardial metabolism of glucose, lactic acid, amino acids and fatty acids in healthy human individuals at rest and at different work loads. Scand. J. Clin. Lab. Invest. 13: 418.

22. Lonsdale, D., W. R. Faulkner, J. W. Price, and R. R. Smeby. 1969. Intermittent cerebellar ataxia associated with hyperpyruvic acidemia, hyperalaninemia and hyperalaninuria. Pediatrics. 43: 1025.

23. Gagnan-Brunette, M., B. Hazel, and C. R. Scriver. 1969. Thiamine dependent neonatal lactic acidosis. Clin. Res. 17: 659. (Abstr.)

24. Hultman, E. 1967. Studies on muscle metabolism of glycogen and active phosphate in man with special reference to exercise and diet. Scand. J. Clin. Lab. Invest. Suppl. 94. 19: 39.

25. Marliss, E. B., T. T. Aoki, T. Pozefsky, A. S. Most, and G. F. Cahill, Jr. 1971. Muscle and splanchnic glutamine and glutamate metabolism in postabsorptive and starved man. J. Clin. Invest. 50: 814.

26. Miller, L. L. 1962. The role of the liver and the nonhepatic tissues in the regulation of free amino acid 
levels in the blood. In Amino Acid Pools, Proceedings of the Symposium on Free Amino Acids, City of Hope Medical Center, 1961. J. T. Holden, editor. Elsevier, Amsterdam. 708.

27. Young, V. R. 1970. The role of skeletal and cardiac muscle in the regulation of protein metabolism. In Mammalian Protein Metabolism. H. N. Munro, editor. Academic Press, Inc., New York. 4: 585.

28. Bowman, R. H. 1966. Effects of diabetes, fatty acids, and ketone bodies on tricarboxylic acid cycle metabolism in the perfused rat heart. J. Biol. Chem. 241: 3041.

29. Randle, P. J., P. J. England, and R. M. Denton. 1970. Control of the tricarboxylate cycle and its interactions with glycolysis during acetate utilization in rat heart. Biochem. J. 117: 677 .

30. Lowenstein, J., and K. Tornheim. 1971. Ammonia production in muscle: the purine nucleotide cycle. Science (Washington). 171: 397.

31. Carlsten, A., B. Hallgren, R. Jagenburg, A. Svanborg, and L. Werkö. 1967. Arterio-hepatic venous differences of free fatty acids and amino acids. Studies in patients with diabetes or essential hypercholesterolemia, and in healthy individuals. Acta Med. Scand. 181: 199.

32. Malmquist, J., R. Jagenburg, and G. Lindstedt. 1971. Familial protein intolerance: possible nature of enzyme defect. N. Engl. J. Med. 284: 997.

33. Levin, B., V. G. Oberholzer, and L. Sinclair. 1969. Biochemical investigations of hyperammonemia. Lancet. 2: 170 .
34. Mohyuddin, F., J. C. Rathbun, and W. C. McMurray. 1967. Studies on amino acid metabolism in citrullinuria. Amer. J. Dis. Child. 113: 152.

35. Shih, V. E., M. L. Efron, and H. W. Moser. 1969. Hyperornithinemia, hyperammonemia, and homocitrullinuria: a new disorder of amino acid metabolism associated with myoclonic seizures and mental retardation. Amer. J. Dis. Child. 117: 83.

36. Brosnan, J. T., H. A. Krebs, and D. H. Williamson. 1970. Effects of ischaemia on metabolite concentrations in rat liver. Biochem. J. 117: 91.

37. Marliss, E. B., T. T. Aoki, C. J. Toews, P. Felig, J. J. Connon, J. Kyner, W. E. Huckabee, and G. F. Cahill, Jr. 1971. Amino acid metabolism in lactic acidosis. Amer. J. Med. In press.

38. Wilson, D. W., W. L. Long, H. C. Thompson, and S. Thurlow. 1925. Changes in the composition of the urine after muscular exercise. J. Biol. Chem. 65: 755.

39. Stein, W. H., and S. Moore. 1954. The free amino acids of human blood plasma. J. Biol. Chem. 211: 915.

40. Keul, J., E. Doll, H. Steim, U. Singer, and H. Reindell. 1964. Uber den Stoffwechsel des menschlichen Herzens. Das Verhalten der arteriocoronarvenösen Differenzen der Aminosäuren und des Ammoniak beim gesunden menschlichen Herzen in Ruhe, während und nach korperlicher. Arbeit. Deut. Arch. Klin. Med. 209: 717.

41. Keul, J., E. Doll, and D. Keppler. 1969. Muskelstoffwechsel. Johann Ámbrosius Barth, Munich. 147. 